\title{
ESTIMATION OF CURCUMINOIDS IN CURCUMA KARNATAKENSIS (WHITE TURMERIC) - AN ENDEMIC TAXON
}

\author{
TEJAVATHI DH ${ }^{1 *}$, SUJATHA BS ${ }^{1}$, KANNAN R ${ }^{2}$
}

${ }^{1}$ Department of Botany, Bengaluru University, Bengaluru - 560 056, Karnataka, India. ${ }^{2}$ Metabolomics Facility, National Centre for Biological Science, GKVK, Bengaluru - 560 065, Karnataka, India. Email: tejavathi_hanu@yahoo.com

Received: 26 June 2017, Revised and Accepted: 09 August 2017

\section{ABSTRACT}

Objective: To estimate the contents of curcuminoids in two samples of Curcuma karnatakensis collected from different localities.

Methods: Quantification of curcuminoids was estimated by ultra-high performance liquid chromatography-mass spectrometry/selected reaction monitoring (UHPLC-MS/SRM) method in two samples of C. karnatakensis for the first time. Fine powder of rhizomatous rootstocks of two plant samples collected from different habitats were served as Samples A and B. The MS used for the metabolite analysis is a Vantage TSQ triple stage quadrupole MS equipped with heated electrospray ionization. The MS is coupled with an Agilent 1290 infinity UHPLC system. A stock solution of curcuminoid standard was prepared by dissolving $5 \mathrm{mg}$ of standard in $1 \mathrm{~mL}$ of methanol. Seven different concentrations of standard (0.15-10 ng on column) were injected for the UHPLC-MS/SRM analysis. Separations were performed using a C-18 column with a flow rate of $0.2 \mathrm{~mL} / \mathrm{minute}$.

Results: Contents of curcumin, demethoxycurcumin, and bisdemethoxycurcumin were found to be varied in two samples and lowest than any other species of Curcuma studied. Variation in the contents may be due to their different habitats in which they are growing.

Conclusion: The present attempt of analyzing the contents of curcuminoids in this endemic taxon for the first time will provide the basis for further pharmacological analysis to authenticate the efficacy of these active principles as the curcuminoids are known for varied pharmacological activities.

Keywords: Curcuma karnatakensis, White turmeric, Zingiberaceae, Endemic, Curcuminoids, Ultra-high performance liquid chromatography-mass spectrometry/selected reaction monitoring.

(C) 2017 The Authors. Published by Innovare Academic Sciences Pvt Ltd. This is an open access article under the CC BY license (http://creativecommons. org/licenses/by/4. 0/) DOI: http://dx.doi.org/10.22159/ajpcr.2017.v10i11.21026

\section{INTRODUCTION}

The taxa categorized under the genus Curcuma of the family Zingiberaceae are known for their medicinal properties. The rhizome of known species of Curcuma yield a yellow - orange and flavor powder when dried and ground except Curcuma zedoaria, which is known as white turmeric that yield white powder. Curcuma longa commonly referred as turmeric, has a long history of use in food and as medicine. A yellow powder obtained from dried rhizome of $C$. longa has been associated with various pharmacological activities such as anti-inflammatory, antiviral (against human immunodeficiency virus), and anticancerous [1-4]. The three main constituents (curcumin, demethoxycurcumin, and bisdemethoxycurcumin) of turmeric powder have been identified as active ingredients, which are responsible for the various pharmacological activities, attributed to C. longa $[5,6]$. Extensive phytochemical and pharmacological studies were conducted in $C$. longa to estimate the curcuminoids and to study their biological activities [7-10]

Curcuma karnatakensis Amalraj, Velayudhan, and Muralidharan is endemic to Karnataka and reported from only two places. The type locality is near Hirehalli which falls under Western Ghats range of Karnataka region, India [11]. The other locality from where this taxon is reported is Dharwad, Karnataka - plain region with different climatic conditions [12]. It is a perennial as other members of Zingiberaceae and grows under shade in red-clay soil (Fig. 1a). The fully grown plant has a short rootstock with stipitate tubers, which are fusiform or conical, white inside (Fig. 1b). During the month from May to September, a spike inflorescence with pale yellow and rosy flowers emerges from the ground followed by broadly ovate dark green leaves (Fig. 1c). Leaves are broadly ovate-elliptic horizontal; petiole shorter than lamina. Inflorescence is spike, which is either lateral or central with pinkishgreen bracts. Flowers are rose-to-rosy white with pale yellow corolla tube that has three rose-colored lobes (Fig. 1d). Labellum is three lobed; middle lobe is large, deeply bifid with bright yellow band in the center. Staminoides are multi-colored; terminal part - white, middle part -rose, and basal part - pale yellow. Anther is white with downward pointing rose-colored spur; ovary trilocular with axile placentation.

Except the above taxonomic description and an attempt to raise multiple shoots through in vitro culture, the plant is totally under exploited in respect of its chemical constituents-active principles [13]. Unlike the other members of Curcuma the dried rhizomatous rootstocks yield white powder as in $C$. zedoaria which is also well known for its medicinal properties and high starch content $[14,15]$. Hence, the objective of present study is to estimate the contents of curcuminoids in the rhizomatous rootstocks of $C$. karnatakensis as a step forward towards the understanding of its pharmacological importance.

\section{METHODS}

\section{Plant source}

Two samples were collected from their natural habitat. The specimens were collected during flowering season, i.e., from May to September. The Holotype - Amalraj 807 (MH) is deposited in National Bureau Plant Genetic Resources New Delhi at Thrissur, Kerala state, India [11]. Authenticated herbarium of the specimens of Sample A is deposited in the department of Botany, Karnatak Science College, Dharwad, Karnataka [12]. The herbarium of the two samples studied in the present investigation were authenticated accordingly and deposited in the Department of Botany, Bengaluru University, Bengaluru - (Voucher number: BUB 202 and 203).

\section{Sample preparation}

Rhizomatous rootstocks were air-dried for 6 days, cut into small segments before crushed into a fine powder with the help of pestle and 
mortar, and stored at $4^{\circ} \mathrm{C}$ until analysis and quantification. High purity MS grade solvents such as methanol and acetonitrile were obtained from Merck Millipore (Merck Millipore India Pvt., Ltd., Bengaluru). Metabolites were extracted from $10.5 \mathrm{mg}$ of the dried powder of both samples using $1 \mathrm{~mL}$ of methanol (vortexed and sonicated for 3 minutes). After centrifugation at 13,000 rpm for 5 minutes the supernatant was dried under speed vacuum. It was then reconstituted in $50 \mu \mathrm{L}$ methanol and injected $10 \mu \mathrm{L}$ for the analysis by ultra-high performance liquid chromatography (UHPLC) - MS/selected reaction monitoring (SRM) method.

\section{Standard preparation}

Pure mixture of curcuminoids was procured from Sd-fine chemicals, India. A stock solution was prepared by dissolving $5 \mathrm{mg}$ of standard in $1 \mathrm{~mL}$ of methanol and stored at $4^{\circ} \mathrm{C}$.

\section{UHPLC - MS conditions}

UHPLC

An Agilment 1290 infinity UHPLC instrument (Agilent technologies India Pvt., Ltd., India) was coupled to the MS to achieve chromatographic separation. It is equipped with column, oven, auto samplers, and thermocontroller. Separations were performed using a C-18 column (Shim-Pack XR-ODS111, $2.1 \times 150 \mathrm{~mm}, 2 \mu \mathrm{m}$ ) with a flow rate of $0.2 \mathrm{~mL} /$ minute. Mobile phase A contains $10 \mathrm{mM}$ of ammonium acetate in water along with $0.1 \%$ of formic acid. Whereas mobile Phase B is acetonitrile with $0.1 \%$ formic acid. A linear gradient was initiated with a following program: $5 \% \mathrm{~B}$ at $0-2$ minutes, $25 \% \mathrm{~B}$ at 3 minutes, 25$100 \% \mathrm{~B}$ at $3-10$ minutes, $100 \% \mathrm{~B}$ at $10-12$ minutes, and finally $5 \% \mathrm{~B}$ at 12-17 minutes. The temperature in the column oven was maintained at $40^{\circ} \mathrm{C}$ and in the auto sampler was at $10^{\circ} \mathrm{C}$. The sample $(10 \mu \mathrm{L})$ was injected using flow through needle injection mode with a total run time of 17 minutes. To avoid the carry over problem, we have enabled needle wash with acetonitrile $(0.1 \%$ formic acid) before sample injection.

\section{$M S$}

The MS (thermo scientific - TSQ vantage) was operated in positive ionization mode. The operating conditions were as follows: Spray voltage $-3500 \mathrm{~V}$; Vaporizer temperature $-100^{\circ} \mathrm{C}$; Sheath gas flow rate20 (arbitrary units) and auxiliary gas flow rate -10 (arbitrary units) collision gas: Organ S-lens voltage and collision energy optimized for curcuminoids were incorporated in the method; Scan time is $50 \mathrm{~ms} /$ transition. The MS-injector setting of 0-3 minutes for waste, 3-12 minutes for load, and again 12-15 minutes for waste. To check the most intense product ions (MS/MS scans), we have infused $10 \mu \mathrm{g} / \mathrm{mL}$ solution of curcuminoids at a flow rate of $5 \mu \mathrm{L} /$ minutes through inbuilt

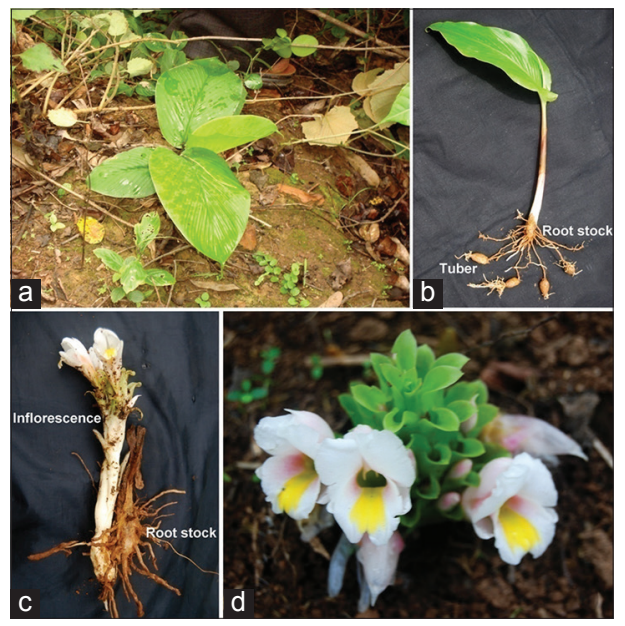

Fig. 1: Curcuma karnatakensis - morphology. (a) plant in wild habitat; (b) plant with rootstock and stipitate tubers; (c) plant with rootstock and spike inflorescence; (d) spike inflorescence with fully bloomed flowers syringe pump. We have used collision-induced dissociation and applied collision energy to the precursor ion and monitored the product ions. The third quadrupole scan was set from m/z 50-500 with a cycle time of 1 second to look at the produc tions. The optimized S-lens voltage and collision energy were used to obtain the most intense product ions for curcuminoids. Seven different concentrations of standard (0.15$10 \mathrm{ng}$ on column) were injected for the UHPLC-MS/SRM analysis. For curcumin $(369 \rightarrow 177)$, demethoxycurcumin $(399 \rightarrow 255)$, and bisdemethoxycurcumin $(309 \rightarrow 224)$ transitions were selected. The area under the peak was used to construct the standard curve and to calculate the concentrations of curcuminoids from sample.

\section{RESULTS AND DISCUSSIONS}

Quantification of curcuminoids in two samples of C. karnatakensis was carried out for the first time following UHPLC-MS/SRM method. MS-based target quantification of biological extracts is considered as quite precise and reliable because of its specificity, sensitivity, and selectivity [16-18]. Goren et al. [5] have compared NMR with LC-MS/MS method for quantification of curcumin in commercial turmeric samples. They are of the opinion that LC-MS/MS method is more suitable for trace analysis of curcumin, while NMR technique for rapid analysis. While Paramasivam et al. [19] have quantified the curcuminoids by HPTLC method citing its advantages such as shorter analysis time and minimal sample preparation. Jayaprakasha et al. [10] employed improved HPLC method for the determination of curcuminoids. Contents of curcumin, demethoxycurcumin, and bisdemethoxycurcumin were found to be $1.06 \pm 0.061$ to $5.65 \pm 0.040 \%, 0.83 \pm 0.047$ to $3.36 \pm 0.040 \%$, and $0.42 \pm 0.036$ to $2.16 \pm 0.06 \%$, respectively, in four different samples of commercially available curcumin. C. zedoaria, known as white turmeric is a well-known ethnomedicinal plant that is also used in Ayruveda. Paramapojn and Gritsanapan [20] have analyzed curcuminoids in ethanolic extracts of C. zedoaria and found an average of $2.73 \pm 1.24 \% \mathrm{w} / \mathrm{w}$ of curcumin, average of $7.37 \pm 2.71 \% \mathrm{w} / \mathrm{w}$ of demethoxycurcumin and average of $1.40 \pm 0.82 \% \mathrm{w} / \mathrm{w}$ of bisdemethoxycurcumin. We have used the highly sensitive UHPLC-MS/ SRM method to quantify the curcuminoids. When the stock solution was injected (10 ng on column), curcumin is the most abundant compared to the other two curcuminoids. We have checked the MS/MS spectrum of curcuminoids to select the specific product ion for the quantification. Both curcumin and demethoxycurcumin showed $177 \mathrm{~m} / \mathrm{z}$ as one of the major product ions and in the bisdemethoxycurcumin, $149 \mathrm{~m} / \mathrm{z}$ as a major product ion. We have selected these product ions for the quantification of both standards and samples. All three showed clear sharp eluting peaks in the gradient elution. Bisdemethoxycurcumin eluted slightly before at 9.47 minutes, demethoxycurcumin was at 9.59 minutes and curcumin at 9.74 minutes (Fig. 2). Since curcumin is abundant $(90 \%)$ in the curcuminoid standard; we have calculated the concentration of demethoxycurcumin and bisdemethoxycurcumin derivatives based on the curcumin amount. We have constructed sevenpoint standard curve (0.15-10 ng on column) from the stock solution to calculate the concentration of curcuminoids in the samples. It looks like there is around $10 \%$ (1.19 $\mathrm{ng}$ ) of demethoxycurcumin and $0.1 \%$ $(0.14 \mathrm{ng})$ of bisdemethoxycurcumin present in $10 \mathrm{ng}$ of stock. In the same way, we have also calculated the curcuminoids from both samples. As shown in Table 1, the contents of curcumin, demethoxycurcumin, and bisdemethoxycurcumin in Sample A were found to be $0.96 \mathrm{ng}$ $(0.0453 \%), 0.09 \mathrm{ng}(0.0042 \%)$, and $0.02 \mathrm{ng}(0.0009 \%)$ in $2.12 \mathrm{mg}$ of dried powder as against $1.53 \mathrm{ng}(0.0722 \%), 0.14 \mathrm{ng}(0.0066 \%)$, and $0.01 \mathrm{ng}(0.0005 \%)$ the Sample B, respectively (Fig. 2).

It is well established that biosynthesis of active principles in medicinal plants is largely depends on the environmental conditions $[21,22]$. Variations found in the contents of curcuminoids in two samples may be due to their two different habitats - Sample A growing in plains, whereas Sample B growing in Western Ghats region. Akbar et al. have found variations in the curcumin content in 131 genotypes collected from different agro climatic zones of India [23]. According to Liu et al. [24] the annual average precipitation and soil organic matter are two important limiting factors that have caused $98.13 \%$ 


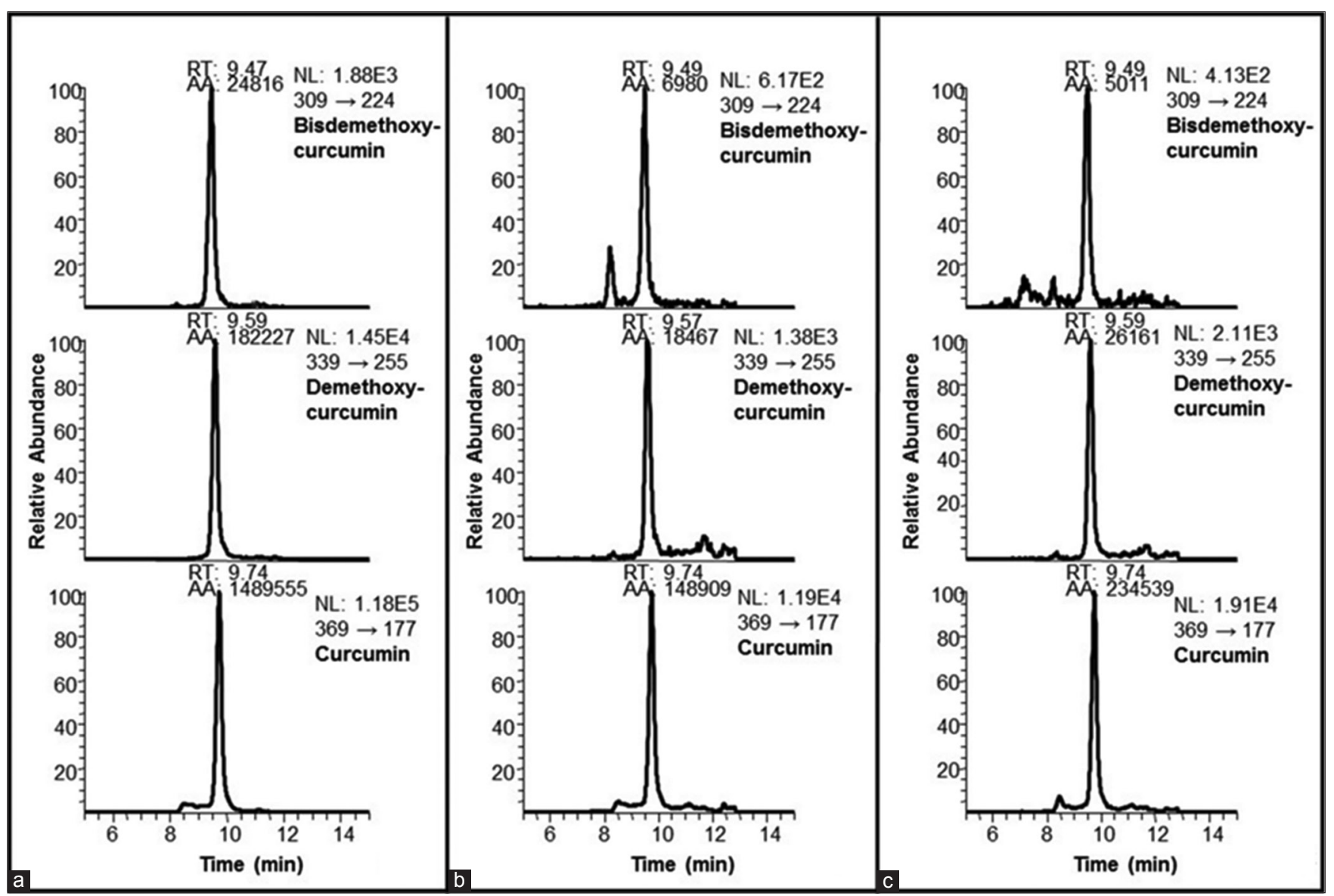

Fig. 2: Ultra-high performance liquid chromatography-mass spectrometry/selected reaction monitoring chromatogram - (a) curcuminoid standard, (b) Sample A and (c) Sample B

Table 1: Contents of curcuminoids in sample A and B of $C$. karnatakensis analyzed by UHPLC-MS/SRM method

\begin{tabular}{lllll}
\hline Samples & Area & Slope & Intercept & Concentrations (ng) (\%) \\
\hline Sample A & & & & $0.96(0.0453)$ \\
$\quad$ Curcumin & 137510 & 139039 & 3664 & $0.09(0.0042)$ \\
Demethoxycurcumin & 16216 & 139039 & 3664 & $0.02(0.0009)$ \\
Bismethoxycurcumin & 6305 & 139039 & 3664 & $1.53(0.0722)$ \\
Sample B & & & & $0.14(0.0066)$ \\
Curcumin & 216142 & 139039 & 3664 & $0.01(0.0005)$ \\
Demethoxycurcumin & 23642 & 139039 & 3664 & 3664 \\
Bismethoxycurcumin & 4372 & 139039 & 0.0039
\end{tabular}

C. karnatakensis: Curcuma karnatakensis, UHPLC: Ultra-high performance liquid chromatography, MS: Mass spectrometer, SRM: Selected reaction monitoring

of the total geographical variation of the active ingredient contents in Sinopodophyllum hexandrum. As Sample B, growing in Western Ghats receives more annual average precipitation and exposed to significantly more organic matter compared to Sample A which grows in plains. However, in S. hexandrum, the annual average precipitation and altitude are negatively correlated and organic matter is positively correlated with the contents of active ingredients. Whereas the contents of active principles in Sinapsis alba was reported to have enhanced with increased precipitation as in the present study [25]. Liu et al. [22] have however reported that the effect of various environmental factors on the contents of active ingredients varies with the type of the secondary metabolite and on the taxon. Altitude has negative correlation with the contents of tannins and shown positive correlation with the contents of flavonoids and rutin in populations of Potentilla fruticosa collected from different localities in China [22]. Arya et al. have correlated the antioxidant potential of $C$. longa to geographical and climatic conditions and concluded that the occurrence of bioactive compounds can be affected by these conditions [26].

\section{CONCLUSION}

The content of curcuminoids in C. karnatakensis was quantified using UHPLC-MS/SRM method that is considered as highly sensitive and can analyze small quantities in the sample. Perusal of literature reveals that the amount of curcuminoids detected in the present samples is the lowest reported so far in any other species of Curcuma including C. zedoaria - white turmeric. Further phytochemical and pharmacological studies are needed to ascertain the efficacy of these active principles in C. karnatakensis.

\section{ACKNOWLEDGMENT}

Thanks are due to UGC, New Delhi for granting BSR-Faculty fellowship for one of the author (DHT). The present work was carried out under this fellowship. Authors are thankful to Metabolomics Facility, C-CAMP, NCBS campus, GKVK, Bengaluru for providing facilities to do this work. 


\section{REFERENCES}

1. Ahsan H, Parveen N, Khan NU, Hadi SM. Pro-oxidant, anti-oxidant and cleavage activities on DNA of curcumin and its derivatives demethoxycurcumin and bisdemethoxycurcumin. Chem Biol Interact 1999;121(12):161-75.

2. Kim DS, Park SY, Kim JK. Curcuminoids from Curcuma longa L. (Zingiberaceae) that protect PC12 rat pheochromocytoma and normal human umbilical vein endothelial cells from betaA(1-42) insult. Neurosci Lett 2001;303(1):57-61.

3. Reddy GK, Chandrakasan G, Dhar SC. Studies on the metabolism of glycosaminoglycans under the influence of new herbal antiinflammatory agents. Biochem Pharmacol 1989;38(20):3527-4.

4. Simon A, Allais DP, Duroux JL, Basly JP, Durand-Fontanier S, Delage C. Inhibitory effect of curcuminoids on MCF-7 cell proliferation and structure-activity relationships. Cancer Lett 1998;129(1):111-6.

5. Goren AC, Cikrikci S, Cergel M, Bilsel G. Rapid quantitation of Curcumin in turmic via NMR and LC-tandem mass spectrometry. Food Chem 2009;113(4):1239-42.

6. Peret-Almeida L, Cherubino AP, Alves RJ, Dufosse L, Gloria BA. Separation and determination of the physic-chemical characteristics of curcumin, demethoxycurcumin and bisdemethoxycurcumin. Food Res Internat 2005;38:1039-44.

7. Coorey RV, Hakansson P. Application of mass spectrometry to characterize the components present in a Curcumin sample. Sri Lankan J Phys 2003;4:11-20.

8. Hiserodt R, Hartman TG, Ho CT, Rosen RT. Characterization of powdered turmeric by liquid Chromatography-mass spectrometry and gas chromatography-mass spectrometry. J Chromatogr A 1996;740:51-63.

9. Cao Y, Xu RX, Liu Z. A high-throughput quantification method of curcuminoids and curcumin metabolites in human plasma via highperformance liquid chromatography/tandem mass spectrometry. J Chromatogr B Analyt Technol Biomed Life Sci 2014;949-950:70-8.

10. Jayaprakasha GK, Jagan Mohan Rao L, Sakariah KK. Improved HPLC method for the determination of curcumin, demethoxycurcumin, and bisdemethoxycurcumin. J Agric Food Chem 2002;50(13):3668-72.

11. Amalraj VA, Velayudhan KC, Muralidharan VK. Curcuma karnatakensis sp. nov. (Zingiberaceae) - A new species from Uttar Kannad district of Karnataka state. J Econ Tax Bot 1991;15:490-2.

12. Kotresha K, Kambhar SV, Harihar NS. Curcuma karnatakensis. In: Amalraj VA, Velayudhan KC, Muralidharan VK, editors. A new record from Dharwad, Karnataka State. In: Proceedings of XVIII Annual conference of Indian Association of Angiosperm Taxonomy and International Seminar on Multidisciplinary approaches in Angiosperm
Systematics. Kalyani, India: University of Kalyani; 2008. p. 520-2.

13. Tejavathi DH, Sujatha BS. In vitro propagation of Curcuma karnatakensis-an endemic taxon. Int J Trop Agric 2016;34(6):1755-60.

14. Lobo R, Prabhu KS, Shirwaikar A, Shirwaikar A. Curcuma zedoaria Rosc. (White turmeric): A review of its chemical, pharmacological and ethno medicinal properties. J Pharm Pharmacol 2009;61(1):13-21.

15. Leonel M, Sarmento SB, Cereda MP. New starches for the food industry: Curcuma longa and Curcuma zedoaria. Carbohydr polym 2003;54:385-8.

16. Padma R, Kannan R. A UHPLC-MS/SRM method for analysis of phenolics from Camellia sinensis leaves from Nilgiri hills. Anal Methods 2016;8:8033-41.

17. Kannan R, Varalaxmi BA, Gowda M. UHPLC-MS/SRM method for quantification of neem metabolites from leaf extracts of Meliaceae family plants. Anal Methods 2016;8:2020-31

18. Dai W, Qi D, Yang T, Lv H, Guo L, Zhang Y, et al. Non targeted analysis using ultra performance liquid chromatography-quadrupole time of flight mass spectrometry uncovers the effects of harvest season on the metabolites and taste quality of tea (Camelia Sinensis L.). J Agric Food Chem 2015;63(44):9869-78

19. Paramasivam M, Poi R, Banerjee H, Bandyopadhyay A. Highperformance thin layer chromatographic method for quantitative determination of curcuminoids in Curcuma longa germplasm. Food Chem 2009; 113(2):640-4.

20. Paramapojn S, Gritsanapan W. Variation of curcuminoids in ethanolic extracts of Curcuma zedoaria rhizome in Thailand by HPLC. Planta Med 2007;73:797-1034.

21. Dong JE, Ma XH, Wei Q, Peng SB, Zhang SC. Effects of growing location on the contents of secondary metabolites in the leaves of four selected superior clones of Eucommia ulmoides. Ind Crops Prod 2011;34(3):1607-4.

22. Liu W, Yin D, Li N, Hou X, Wang D, Li D, Liu J. Influence of environmental factors on the active substances production and antioxidant activity in Potentilla fruticosa $\mathrm{L}$. and its quality assessment. Sci Rep 2016;6:e28591.

23. Akbar A, Kuanar A, Sandeep IS, Kar B, Singh S, Mohanty S, et al. GC-MS analysis of essential oil of some high drug yielding genotypes of Turmeric (Curcuma longa L.) Int J Pharm Pharm Sci 2015;7(9):35-40.

24. Liu W, Liu J, Yin D, Zhao X. Influence of ecological factors on the production of active substances in the anti-cancer plant Sinopodophyllum hexandrum (Royle)T.S.Ying. PLoS One 2015;10(4):e0122981.

25. Liu J, Xu XJ. Meteorology. Beijing: China Agricultural Press; 2002.

26. Arya N, Prakash O, Verma AK, Pant AK. Variation in antioxidant potential of Curcuma longa $\mathrm{L}$. Collected from different ecological niches of Western Himalayan region. Int J Pharm Pharm Sci 2015;7(7):85-90. 